\title{
An analysis of the effects of nanoparticles deposition on characteristics of the heating surface and $\mathrm{ON}$ pool boiling of water
}

\author{
I.S. Kiyomura ${ }^{a}$, L.L. Manetti ${ }^{a}$, A.P. da Cunha ${ }^{a}$, G. Ribatski ${ }^{b}$, E.M. Cardoso ${ }^{a, *}$ \\ ${ }^{a}$ UNESP - Univ Estadual Paulista, Department of Mechanical Engineering, Av. Brazil Centro 56, 15385-000 Ilha Solteira, SP, Brazil \\ ${ }^{\mathrm{b}}$ Heat Transfer Research Group, Department of Mechanical Engineering, Escola de Engenharia de São Carlos (EESC), University of São Paulo (USP), Brazil
}

\section{A R T I C L E I N F O}

\section{Article history:}

Received 7 July 2016

Received in revised form 14 September

2016

Accepted 16 September 2016

Available online 22 September 2016

\section{Keywords:}

Boiling heat transfer

Nanofluid

Nanostructured surface

Heat transfer coefficient

\begin{abstract}
A B S T R A C T
Nanofluid pool boiling can modify the morphology of the heating surface and the physical properties of the base fluids, interfering directly on the vapor bubbles dynamics and on the heat transfer mechanisms. This paper concerns an experimental investigation of the effects of surface roughness and nanoparticle deposition on the contact angle, surface wettability and pool boiling heat transfer coefficient (HTC). Experiments were carried out using copper surfaces with different roughnesses, and deionized water as the working fluid at a pressure of $98 \mathrm{kPa}$ and under saturated conditions. The nanostructured surfaces were produced by maghemite nanoparticle deposition, which is achieved by boiling selected mass concentrations of a $\mathrm{Fe}_{2} \mathrm{O}_{3}$-deionized water nanofluid $(0.029 \mathrm{~g} / \mathrm{l}$ and $0.29 \mathrm{~g} / \mathrm{l}$, corresponding to low and high nanofluid concentration, respectively). The highest heat transfer coefficients were obtained for the smooth surface with deposition of nanoparticles at low mass concentrations. In addition, as the nanofluid concentration increases the surface roughness also increases, and the higher the nanofluid concentration, the lower the contact angle of water on the coated surface.
\end{abstract}

(c) 2016 Elsevier Ltd. All rights reserved.

\section{Introduction}

In the last years, the development of new products with extremely high thermal loads and the need to produce more efficient and compact heat exchangers, especially in microelectronics, has been motivating the research on new technics for increasing the boiling heat transfer.

Since the work of Fritz [1], who was the first to study the effect of surface characteristics on the boiling process, several surface modification methods have been proposed in order to increase the heat transfer coefficient (HTC) and the critical heat flux (CHF) under pool boiling conditions. In this context, Yang and Maa [2] were pioneers to evaluate the effect on the heat transfer coefficient of nanoparticles deposition on the heated surface through a boiling process. According to their study, the thermal boundary layer is modified by the presence of nanoparticles which, in turn, is expected to change the boiling behavior. Since then, innumerous researchers conducted tests on nucleate pool boiling using nanostructured surfaces (see the reviews of [3-5] for a broad prospect on the literature concerning this topic). The studies concerning nanostructured surfaces through a boiling process share, as a common

\footnotetext{
* Corresponding author.

E-mail address: elainemaria@dem.feis.unesp.br (E.M. Cardoso).
}

result, the enhancement of the CHF [6-9] by depositing nanoparticles on the surface. However, conflicting results and behaviors have been pointed out by studies concerning experimental evaluations of the heat transfer coefficient during pool boiling on nanostructured surfaces [8-12]. Heitich et al. [8] analyzed the effect of nanostructured surfaces on pool boiling of water under saturated conditions. In their experiment, the nanostructured surface consisted of a Constantan tape nanocoated with molybdenum (achieved by sputtering process) and maghemite (obtained by nanofluid evaporation). Intensification in the surface wettability of the nanocoated surfaces was observed, what was pointed out as the reason for the CHF augmentation. Also, HTC enhancement for the roughest surface was detected, while for the smoother surfaces the HTC was enhanced by the nanoparticle deposition only for high heat fluxes.

Souza et al. [9] studied the effect of deposition of $\gamma-\mathrm{Fe}_{2} \mathrm{O}_{3}$ nanoparticles (10 and $80 \mathrm{~nm}$ diameter) on a horizontal surface (with a surface roughness, $R_{a}=0.16 \mu \mathrm{m}$ ), using HFE7100 (a highly wetting fluid) as working fluid. Their experiments were performed for unconfined and confined boiling conditions. Souza et al. [9] found an increment of HTC for the nanostructured surface with smaller nanoparticles compared to the surface without deposition. The results for larger nanoparticles showed a decrease in the HTC as compared to the case without deposition. The authors then concluded that characteristics of the microstructure of the heating 


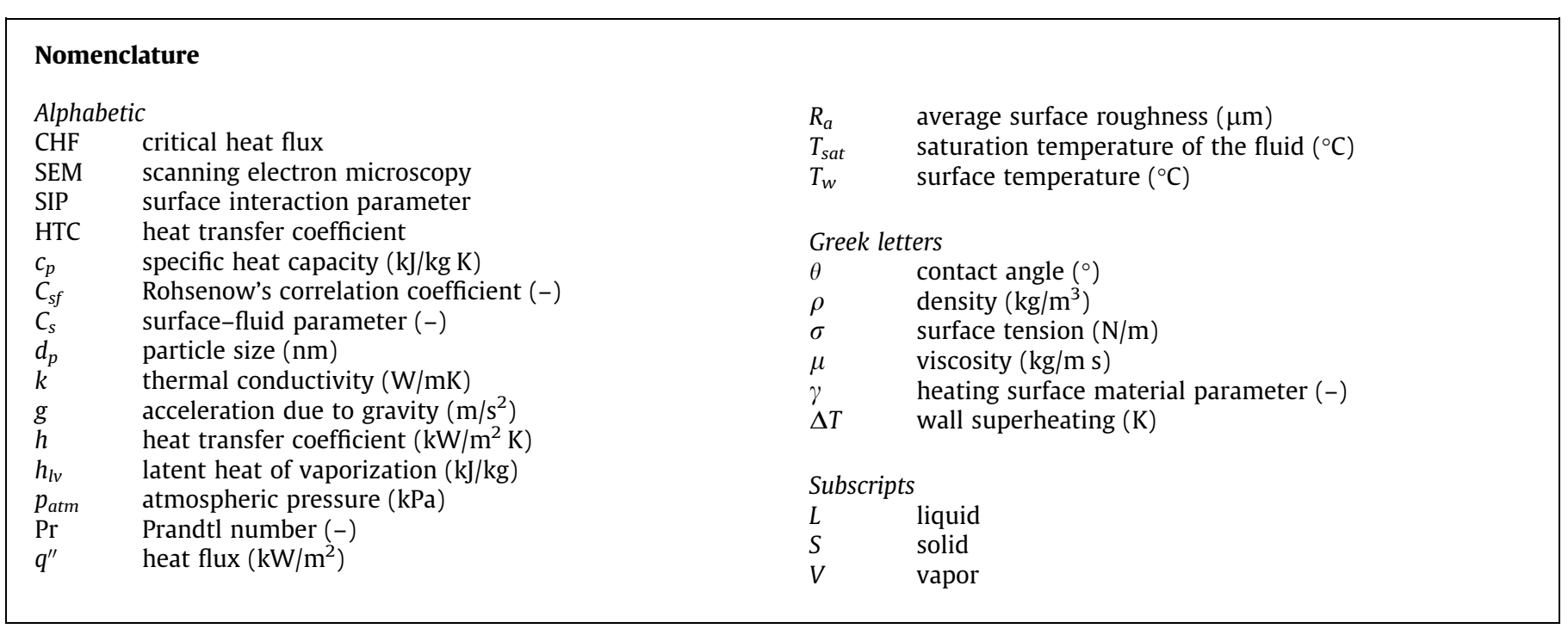

surface, such as quantity and size of surface irregularities, influence the heat transfer process.

Deterioration of HTC was reported by authors that varied the concentration of nanofluids for fixed nanoparticle size and surface roughness [10-12]. Ahmed and Hamed [12] pointed out that nanofluid concentration is also an important parameter to be considered. These authors pointed out that the nanoparticles deposition occurs at a slower rate for low concentrations ( 0.01 vol.\%), which may lead to an increase in the HTC. According to Ahmed and Hamed [12], the rate and uniformity of particles deposition depend on nanofluids concentration. Moreover, these authors suggested that, for low concentrations, the HTC increases mainly due to the increment of convective effects related to the thermal conductivity augmentation, being the contribution of this mechanism more effective than the rate of deposition of nanoparticles on the surface.

In general, it can be concluded from literature analyses that the modification in the behavior of CHF and HTC may be explained by the changes in the surface wettability and in the number and size of microcavities caused by the nanoparticles deposition on the surface. The CHF enhancement is related to the fact that the nanoparticles deposition improves the wettability and the capillary wicking of the heating surface [13-16], thus allowing the fluid located near the surface to rewet the hot spots and to cool down the heating surface. Regarding the modifications in the HTC, the deposition of nanoparticles generates a porous layer on the heating surface that lead to a change in the surface roughness and in the number of microcavities. Some recent works have shown that the HTC behavior also depends on the contact angle, because the frequency of formation of bubbles and their diameter of departure decrease with the thickness of the nanolayer, as summarized by Ignácio et al. [17].

Narayan et al. [18] introduced a surface interaction parameter (SIP), which has been defined as the ratio between the surface roughness and the nanoparticle diameter, $d_{p}$. When SIP $>1$, an enhancement in the HTC was observed, and according to Narayan et al. [18] this behavior occurs due to the nanoparticles deposition in the cavities, splitting a single active cavity into multiple ones. The Narayan parameter was used by other authors [19,20], and seems to be a suitable parameter to predict the interaction between heating surface roughness and deposition of nanoparticles.

Recently, Sarafraz et al. [21] investigated the effect of nanoparticle deposition on a copper flat disc and found out that the HTC increases with decreasing the nanoparticles size. According to the authors, such deposition causes an increase in the wettability, changing the nucleation site density, which can either deteriorate or enhance the boiling heat transfer depending on the size of the irregularities and microstructures on the heating surface. Although the smallest nanoparticles fill the microcavities, which in turn lead to a reduction in the number of active nucleation sites, they form a thin nanoparticle layer on the heating surface, with more irregularities and less thermal resistance as compared with larger nanoparticles.

In this context, the aim of the present work are the following: (i) to analyze the conjugate effect of surface roughness and nanoparticle concentration on the nanocoating process by using the nanofluid boiling technique; (ii) to investigate the effects of the nanocoating on the HTC behavior for pool boiling of DI-water.

\section{Materials and methods}

\subsection{Apparatus assembly}

In the present study, a boiling chamber was used to contain the working fluid during the boiling process. The boiling chamber (Fig. 1) consists of a cube of glass walls $5 \mathrm{~mm}$ thick, and overall dimensions of $170 \times 170 \times 180 \mathrm{~mm}$. The cube involves a hollow

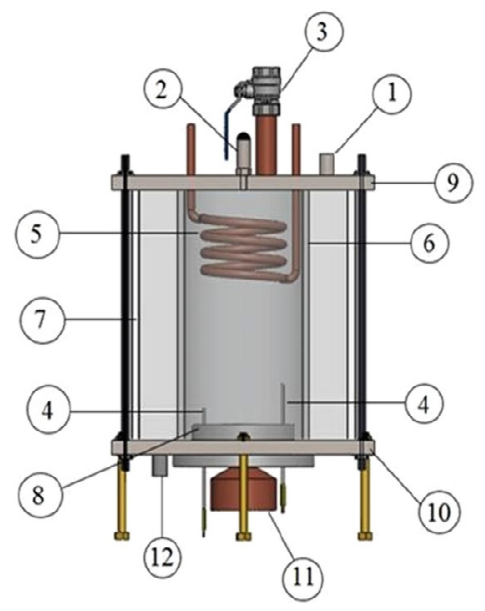

1. Water outlet

2. Pressure transducer

3. Valve

4. Thermocouples

5. Copper coil

6. Glass tube

7. Glass cube

8.

9. Upper stainless steel plate

10. Lower stainless steel plate

11. Copper block

12. Water inlet

Fig. 1. Boiling chamber design. 


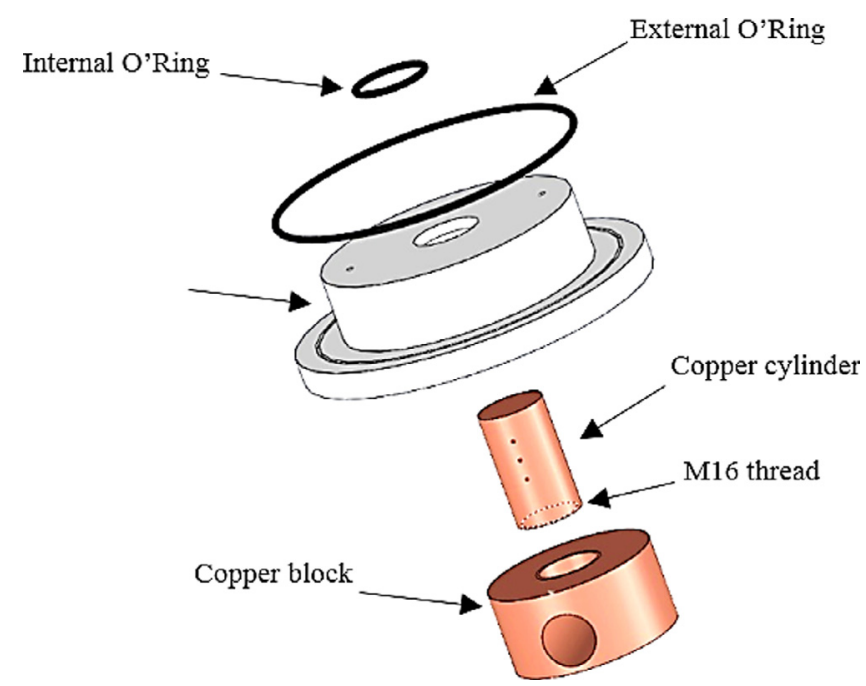

Fig. 2. View of the test section assembly.

borosilicate glass tube of internal diameter of $90 \mathrm{~mm}$, height of $180 \mathrm{~mm}$, and wall thickness of $10 \mathrm{~mm}$.

The cube and the tube are fixed between two plates of stainless steel AISI 316 with dimensions of $200 \times 200 \times 10 \mathrm{~mm}$. Nitrile rubber and silicone are used for sealing the boiling chamber and the glass cube. In the region comprised by the cube and external tube walls, a water forced flow is imposed which temperature is controlled by an ultra-thermostatic bath that maintains the test fluid near the saturation condition $\left(T_{\text {sat }}=99^{\circ} \mathrm{C}\right)$. A second thermostatic bath is used to control the temperature of the water circulating through the condenser (copper coil) located at the top of the boiling chamber. Two K-type thermocouples located within the glass tube in the liquid and vapor regions are used to monitor the test temperature. A pressure transducer measures the pressure inside the boiling chamber, which is maintained close to the atmospheric pressure $\left(p_{a t m}=98 \mathrm{kPa}\right)$ during the pool boiling tests.

The test section (Fig. 2) consists of a copper block (20 mm diameter and $60 \mathrm{~mm}$ height) containing three K-type thermocouples with hot junctions diameters of $0.50 \mathrm{~mm}$ fixed inside $1 \mathrm{~mm}$ diameter holes at the radial center of the copper cylinder. These thermocouples are used to estimate the wall temperature and the heat flux. The holes were filled with copper powder to avoid air gaps inside them. The copper block is heated by a cartridge resistance $(300 \mathrm{~W} / 220 \mathrm{~V})$, capable of providing a maximum heat flux of $1100 \mathrm{~kW} / \mathrm{m}^{2}$ through the test surface. The thermal insulation of the test section consists of $40 \mathrm{~mm}$ thick layers of polytetrafluoroethylene and vermiculite.

\subsection{Test surfaces preparation}

In the present study, the pool boiling performance of six different copper surfaces was analyzed. These surfaces consisted of one smooth surface (SS), one rough surface (RS), two smooth surfaces with nanoparticle deposition (using nanofluids composed of low and high nanoparticles concentration, SS-LC and SS-HC, respectively) and two rough surfaces with nanoparticle deposition (using nanofluids composed of low and high nanoparticles concentration, RS-LC and RS-HC, respectively). All the surfaces were initially polished using an aluminum-oxide abrasive compound (corresponding to smooth surface) or \#600 emery paper (corresponding to rough surface), corresponding to $R_{a}=0.05 \mu \mathrm{m}$ and $0.23 \mu \mathrm{m}$, respectively. Prior to the deposition processes, all surfaces were cleaned with acetone and carefully dried using an air jet.

In order to verify the influence of the nanolayer thickness on the wettability, the nanocoated surfaces were produced by the deposi- tion of nanoparticles via vigorous boiling process of $\mathrm{Fe}_{2} \mathrm{O}_{3}$ deionized water nanofluid, with two different mass concentrations of $0.029 \pm 0.0005 \mathrm{~g} / \mathrm{l}$ (corresponding to low nanofluid concentration) and of $0.29 \pm 0.005 \mathrm{~g} / \mathrm{l}$ (corresponding to high nanofluid concentration). In order to ensure a uniform nanolayer deposited on the surface and to avoid the boiling time effect on the deposition process, the boiling process was maintained during a period of $3 \mathrm{~h}$ for each nanocoated surface.

After the boiling process, the nanofluid was removed from the boiling chamber and the heating surface was used in the boiling tests without removing the layer of deposited nanoparticles.

The water based $\gamma-\mathrm{Fe}_{2} \mathrm{O}_{3}$ nanofluid having an average particle size of $10 \mathrm{~nm}$ was used for nanostructuring the copper surfaces. This nanofluid is synthesized following the method of Massart [22], in which $\mathrm{Fe}_{2}^{+}$and $\mathrm{Fe}_{3}^{+}$salts are precipitated in an alkaline medium and then dispersed in water, and supplied by the NFA Laboratory in the Physics Institute of the University of Brasília.

\subsection{Experimental procedures}

The experiments were conducted using deionized water as the working fluid under saturated conditions at a pressure close to $98 \mathrm{kPa}$. The same procedure was adopted during all the experimental tests in order to ensure repeatability.

Before each run, the working fluid was heated very close to the saturation temperature in order to degas it. No evidence of significant amounts of gas dissolved in the working fluid was detected on the boiling curves. Before each series of measurements, vacuum was created in the boiling chamber and, then, this vessel was immediately fed with the working fluid. The test conditions were regulated by monitoring the pressure and the temperature inside the boiling chamber.

Once the test conditions were stabilized and the boiling process initiated, heat flux values varying from 100 to $800 \mathrm{~kW} / \mathrm{m}^{2}$ were imposed. During the tests, the heat flux was stepwise increased. Stable conditions were characterized by variations on the temperature within the uncertainty of their measurements $\left( \pm 0.4^{\circ} \mathrm{C}\right)$. The heat flux and surface temperature are calculated according to Fourier's Law assuming 1-D conduction based on the wall temperature measurements from the thermocouples embedded in the copper block. The temperature of the boiling surface was then determined by extrapolating the linear temperature profile to the copper block upper surface, $T_{w}$. The setup of the block and the location of the thermocouples are shown in Fig. 3.

Different linear temperature curve fittings were obtained for each heat flux based on the temperature measurements provided by the thermocouples embedded in the copper block. Care was exercised in order to obtain curve fittings with $R$-square always higher than 0.99. Fig. 4 displays the temperature profiles and the curve fittings. According to this figure, the assumption of negligible heat losses in the radial direction seems suitable; otherwise a linear profile would not fit the experimental data. Moreover, a comparison between the imposed heat flux based on the current and voltage measurements, and the heat flux estimated from the linear profile reveals heat losses always lower than $12 \%$.

The temperature readings were acquired from the thermocouples through a data acquisition system from Agilent, 34970A model. The heat transfer coefficient was calculated using the Newton's law of cooling given by

$h=\frac{q^{\prime \prime}}{\Delta T_{\text {sat }}}$

where $\Delta T_{s a t}=T_{w}-T_{s a t}\left(p_{a t m}\right) . T_{w}$ is the wall temperature, and $T_{\text {sat }}\left(p_{\text {atm }}\right)$ corresponds to the saturation temperature of water at local atmospheric pressure $\left(p_{a t m}=98 \mathrm{kPa}\right)$. 


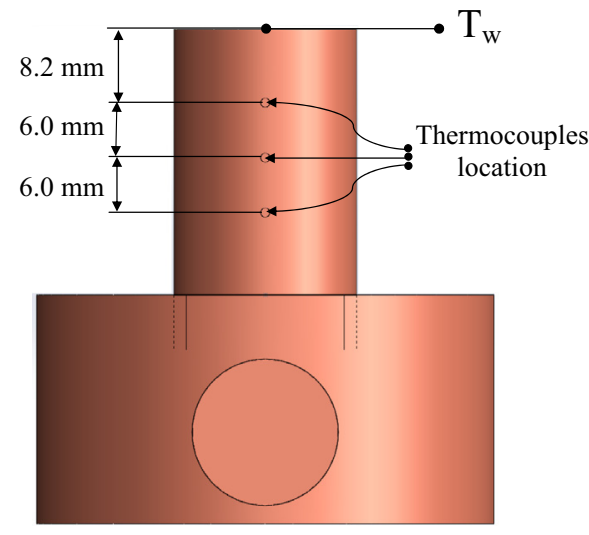

Fig. 3. Schematic drawing of copper heater block.

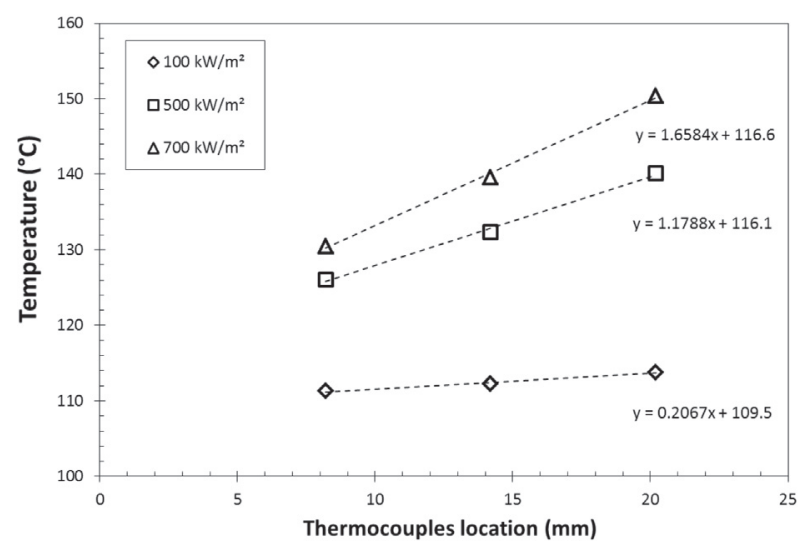

(a)

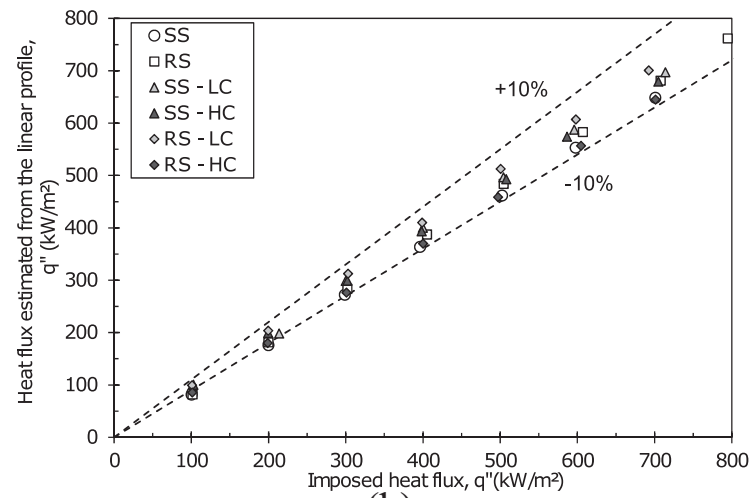

(b)

Fig. 4. (a) Example of linear temperature profiles used to estimate the heat flux and wall temperatures for heat flux of 100,500 and $700 \mathrm{~kW} / \mathrm{m}^{2}$, for rough surface (RS) and deionized water as working fluid. (b) Comparison between the imposed heat flux based on the current and voltage measurements and the heat flux estimated from the linear profile.

In order to ensure the steady state regime was achieved, each test had a duration of $1500 \mathrm{~s}$ for each applied heat flux, but only the temperature data for the last $500 \mathrm{~s}$ (corresponding to 100 experimental data points) of the test interval were considered. The uncertainties of temperature measurements were evaluated according to the procedure proposed by Passos and Reinaldo [23] and a value of $\pm 0.4^{\circ} \mathrm{C}$ was found. The uncertainties for the calculated parameter were estimated according to the method proposed by Taylor and Kuyatt [24]. Based on the linear curve fittings and the uncertainties of temperature measurements and distances among thermocouples and copper block superior surface, the uncertainty of wall temperature was found lower than $\pm 0.5^{\circ} \mathrm{C}$. The experimental uncertainty of heat flux and heat transfer coefficient varied from $15.3 \%$ to $1.6 \%$, and from $15.9 \%$ to $2.6 \%$ respectively. Saturated conditions were assured by keeping the difference between liquid temperature inside the vessel and saturation temperature, estimated from the measured pressure, within a range of $\pm 0.4{ }^{\circ} \mathrm{C}$.

\subsection{Surface characterization techniques}

Prior and after each test, the characteristics of the test surfaces were evaluated using the following procedures:

Structural and chemical information obtained through scanning electron microscope (SEM) with a magnification of $1000 \times$;

- Average surface roughness, obtained for the same scanning area for all surfaces using a rugosimeter Mitutoyo Surftest SJ 301 model with measuring range of $-200 \mu \mathrm{m}$ to $+150 \mu \mathrm{m}$ $( \pm 0.005 \mu \mathrm{m})$;

$\checkmark$ Static contact angles measured at $25{ }^{\circ} \mathrm{C}$ in quiescent air by analysis of pictures of a sessile droplet of water using the experimental apparatus shown in Fig. 5.

It is worth mentioning that all the surfaces after boiling tests look the same as before, without any significant modification in their characteristics.

The apparatus to measure the static contact angle comprises a camera, a green LED light source, a light diffuser and an aluminum plate where the test surface is fixed. The procedure adopted to evaluate the contact angle consists on depositing on the test surface a sessile droplet of water with a volume of $20 \mu \mathrm{l}$ through a syringe pointed vertically down onto the sample. Then, images of the droplet on the surface are captured with a camera. After that, the pictures are analyzed using image post processing software to shape the deionized water droplet. The adopted procedure is well detailed by Netto et al. [25].

The method for evaluating the contact angle was validated based on the same procedure used by Netto et al. [25] and Kiyomura et al. [15] by performing comparisons with standard samples with known angles. These samples consist of semi-spherical pieces namely A, B and C, made of glass, with shapes similar to a droplet positioned on the surface as may observed in Fig. 6 .

After taking pictures of each semi-spherical proof body positioned on the test surface, three distinct operators analyzed each image by measuring the contact angle with help of image post processing software. Table 1 presents a comparison of the contact angle measurements and the respective values estimated based on geometrical relations. Mean absolute error (MAE) lower than $1^{\circ}$ assure the accuracy of the method used in the present study for measuring the contact angle based on sessile droplets.

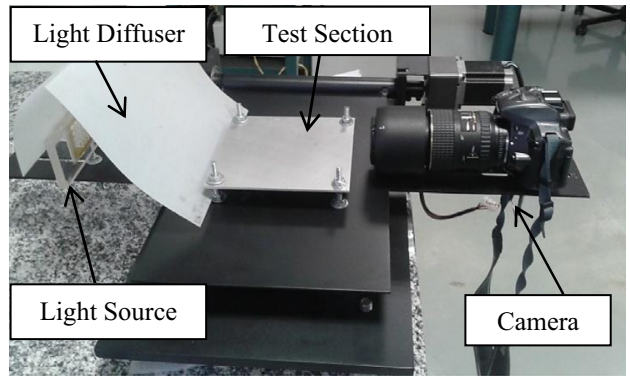

Fig. 5. Experimental apparatus to measure the contact angle of droplets. 
Table 2 presents SEM images of the surfaces evaluated in the present study obtained after the pool boiling experiments with DI-water. It can be observed from these images that as the concentration of the nanofluid used to obtain the nanostructure increases, the layer deposited on the surface becomes thicker and larger microsized structures as protuberances are formed on the surface. On the other hand, for the surface obtained with the nanofluid presenting the lowest nanoparticle concentration, the surface structure is formed by ramified paths and its thickness seems to be lower.

\subsection{Boiling apparatus validation}

In order to validate the boiling apparatus and the experimental procedure, tests were carried out for pool boiling of deionized water on the rough (RS) and smooth (SS) surfaces. The experimental data, the corresponding curve fittings, and predicted values according to the Rohsenow [26] correlation are plotted in Figs. 7a (RS) and $6 \mathrm{~b}$ (SS). The curve fittings were based on the relation of heat transfer coefficient and heat flux for pool boiling, generally expressed as follows,

$h=C q^{\prime \prime n}$

where $C$ is a coefficient that depends on surface-fluid characteristics and $n$ is the exponent of heat flux. The correlation of Rohsenow [26] is given as follows:

$\frac{c_{p l} \Delta T_{s a t}}{h_{l v}}=C_{s f}\left[\frac{q^{\prime \prime}}{h_{l v} \mu_{l}} \sqrt{\frac{\sigma}{g\left(\rho_{l}-\rho_{v}\right)}}\right]^{r} \operatorname{Pr}_{l}^{s}, \quad(s=1 ; r=0.33)$

where $\mu_{l}, h_{l v}, c_{p l}$, and $\operatorname{Pr}_{l}$ are the liquid viscosity ( $\left.\mathrm{kg} / \mathrm{m} \mathrm{s}\right)$, the latent heat of vaporization $(\mathrm{kJ} / \mathrm{kg})$, the liquid specific heat $(\mathrm{kJ} / \mathrm{kg} \mathrm{K})$, and the liquid Prandtl number, respectively. The coefficient $C_{s f}$ is the fluid-surface parameter that depends on the working fluid, the surface material and roughness and how the fluid and surface interacts.

Based on the study of Vachon et al. [27], the present authors adopted $C_{s f}=0.0107$ for RS and $C_{s f}=0.0147$ for SS. As shown in Fig. 7 the present data agrees reasonably well with predictions based on the correlation of Rohsenow [26] and mean absolute errors (MAE) of about $7 \%$ and $4 \%$ are found for the rough and smooth surfaces, respectively. Values of $n$ close to 0.7 were found for the fitted curves. Such a result agrees with the reports of Stephan [28], according to which, for developed nucleate boiling regime, the value of $n$ generally lies between 0.6 and 0.8 .

\section{Results and discussion}

Corty and Foust [29] performed controlled experiments on the surface roughness and found that surface roughness not only influences the wall superheating required for the onset of nucleate boiling $(\mathrm{ONB})$, but also the slope of the boiling curve. The results displayed in Fig. $8 \mathrm{a}$ and $\mathrm{b}$ agree with the results reported by Courty and Foust [29]. According to these authors, for the same heat flux, the rougher surface presents a lower superheating compared to the smoother one. It can be speculated that this behavior is due to the presence of larger unflooded cavities on the rougher surface. In the
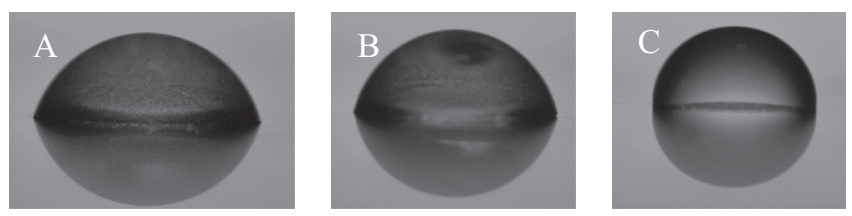

Fig. 6. Semi-spherical proof bodies namely A, B and C positioned on the test surface to validate contact angle measurements.
Table 1

Results of the contact angle measured on three semi-spherical proof bodies simulating droplets.

\begin{tabular}{llll}
\hline & Proof body $\mathrm{A}\left(^{\circ}\right)$ & Proof body B $\left(^{\circ}\right)$ & Proof body $\mathrm{C}\left({ }^{\circ}\right)$ \\
\hline Operator 1 & 76.9 & 81.5 & 93.9 \\
Operator 2 & 74.6 & 80.6 & 94.8 \\
Operator 3 & 76.4 & 80.5 & 94.5 \\
Average value & 76.0 & 80.9 & 94.4 \\
$\mathrm{MAE}=\frac{1}{N} \sum_{i=1}^{N}\left|\frac{\theta_{\text {call }}-\theta_{\text {exp }}}{\theta_{\text {calc }}}\right|$ & 1.0 & 0.9 & 0.5 \\
\hline
\end{tabular}

Table 2

SEM images for all surfaces tested.

\begin{tabular}{|c|c|}
\hline Surfaces & SEM images \\
\hline $\begin{array}{l}\text { Smooth surface (SS) } \\
\text { Surface polished with aluminum-oxide } \\
\quad \text { abrasive compound, without deposition }\end{array}$ & \\
\hline $\begin{array}{l}\text { Rough surface (RS) } \\
\text { Surface polished with \#600 emery paper, } \\
\quad \text { without deposition }\end{array}$ & \\
\hline $\begin{array}{l}\text { SS-Low concentration (SS-LC) } \\
\text { Nanocoated smooth surface via boiling } \\
\text { process of } \mathrm{Fe}_{2} \mathrm{O}_{3} \text {-deionized water } \\
\text { nanofluid, with mass concentration of } \\
0.029 \mathrm{~g} / \mathrm{l}\end{array}$ & \\
\hline $\begin{array}{l}\text { SS-High concentration (SS-HC) } \\
\text { Nanocoated smooth surface via boiling } \\
\text { process of } \mathrm{Fe}_{2} \mathrm{O}_{3} \text {-deionized water } \\
\text { nanofluid, with mass concentration of } \\
0.29 \mathrm{~g} / \mathrm{l}\end{array}$ & \\
\hline $\begin{array}{l}\text { RS-Low concentration (RS-LC) } \\
\text { Nanocoated rough surface via boiling } \\
\text { process of } \mathrm{Fe}_{2} \mathrm{O}_{3} \text {-deionized water } \\
\text { nanofluid, with mass concentration of } \\
0.029 \mathrm{~g} / \mathrm{l}\end{array}$ & \\
\hline $\begin{array}{l}\text { RS-High concentration (RS-HC) } \\
\text { Nanocoated rough surface via boiling } \\
\text { process of } \mathrm{Fe}_{2} \mathrm{O}_{3} \text {-deionized water } \\
\text { nanofluid, with mass concentration of } \\
0.29 \mathrm{~g} / \mathrm{l}\end{array}$ & \\
\hline
\end{tabular}

literature, it is well known that lower wall superheating is needed to activate larger cavities compared to smaller ones. Therefore, the number of active nucleation sites increases with increasing the surface roughness, leading to the decrease of the surface temperature, and consequently, the HTC enhancement.

The experimental results showed that the degree of enhancement or deterioration of pool boiling heat transfer by nanostructured surfaces is strongly affected by the relative size of nanoparticles and original heating surface morphology (roughness). Fig. 9 shows a comparison of the behavior of the HTC with increasing heat flux for the rough surfaces without and with nanoparticles deposition (RS-LC and RS-HC). 


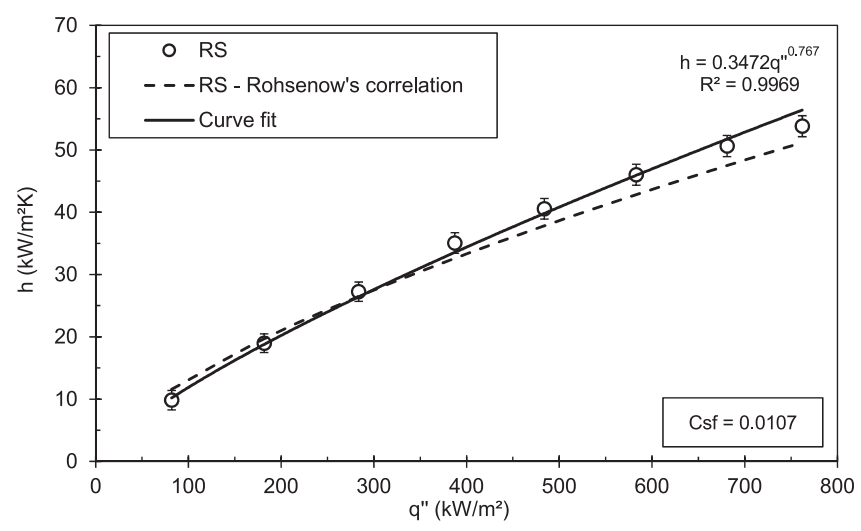

(a)

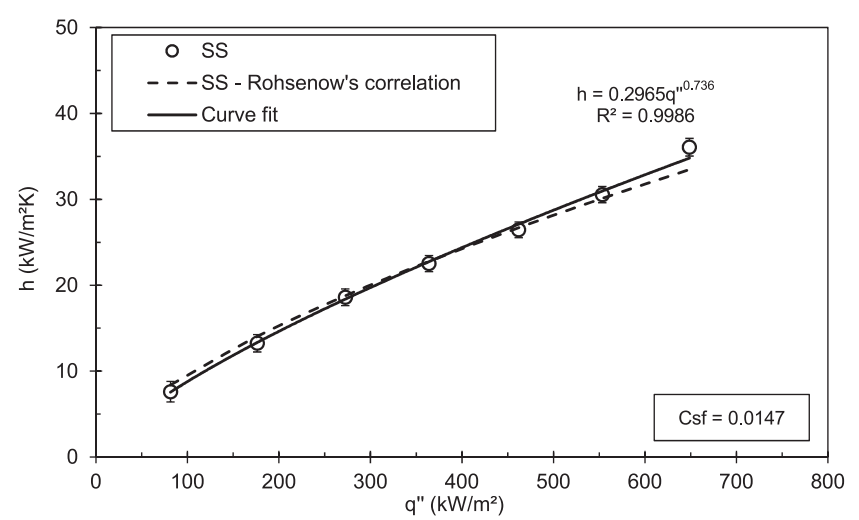

(b)

Fig. 7. Pool boiling apparatus validation using the power curve fitting and the comparison with Rohsenow correlation: (a) rough surface and (b) smooth surface.

Both surfaces (RS-HC and RS-LC) present deterioration of HTC when compared with the surface without deposition. This may be explained by the decrease of nucleation site density, which may affect the bubble frequency and its departure diameter, since the active sites, corresponding to the larger surface cavities, are filled with nanoparticles. As a consequence, cavities with smaller mouth diameter can be formed. However, to maintain active such cavities, higher wall superheating is necessary, which is detrimental to the heat transfer coefficient. Fig. 10 illustrates schematically

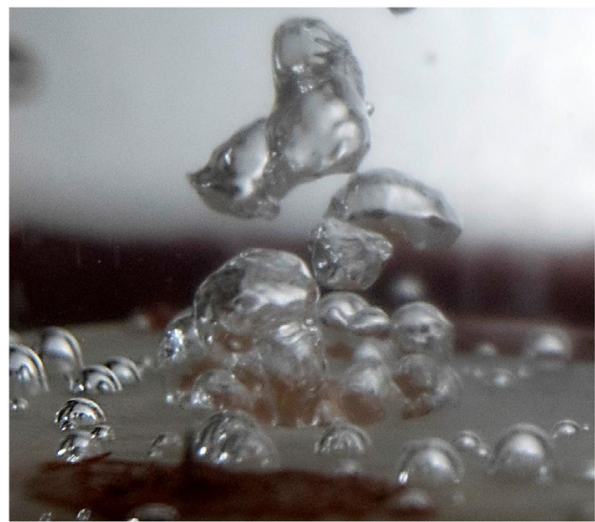

(a)
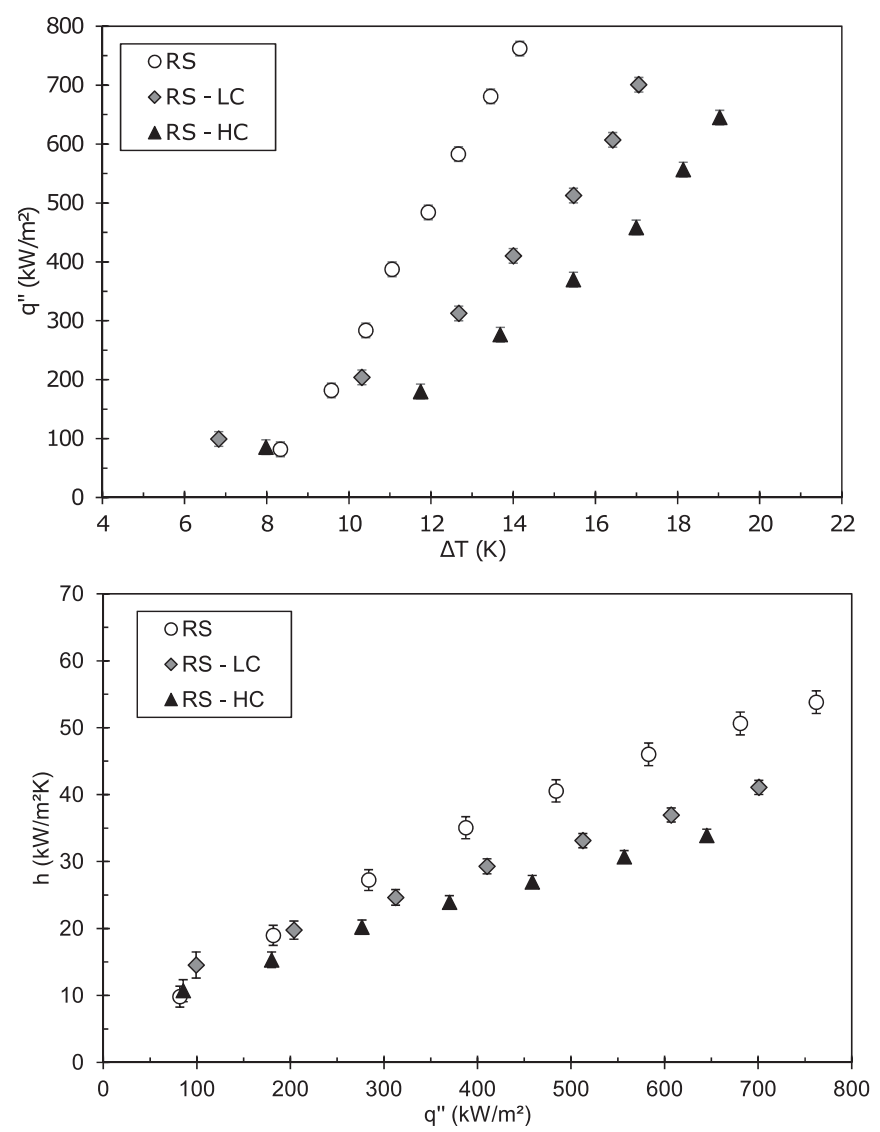

Fig. 9. Boiling curve and HTC curve for rough surfaces with (RS-LC and RS-HC) and without (RS) nanoparticle deposition.

this process. Moreover, as the nanofluid concentration increases, the thickness of the covering layer deposited on the surface also increases, leading to an enhancement of the thermal resistance with consequent degradation of HTC [12]. This fact is corroborated by the SEM images of the rough surfaces show in Table 2, according to which the nanoparticle layer of the RS-HC surface seems thicker than the nanoparticle layer of the RS-LC surface.

Fig. 11 presents the heat transfer coefficient data for the smooth surfaces without and with nanoparticle deposition based on the nanofluids with lower and higher nanoparticles concentrations (SS-LC and SS-HC).

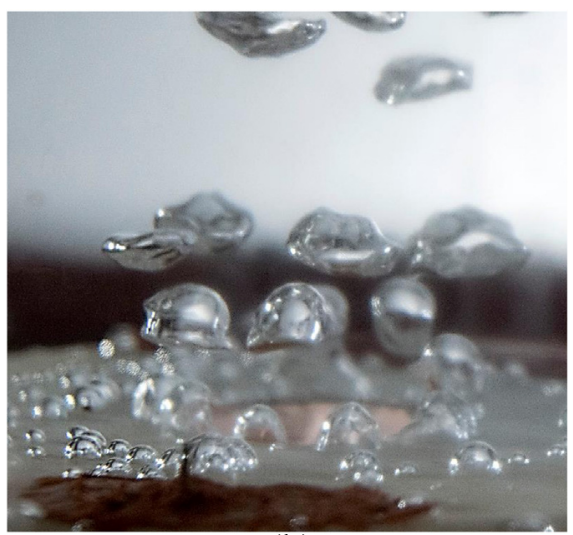

(b)

Fig. 8. Effect of surface roughness for $q^{\prime \prime}=200 \mathrm{~kW} / \mathrm{m}^{2}$ and for surfaces without nanoparticle deposition. (a) Rough surface and (b) smooth surface. 
In general, it can be noted in Fig. 11 that the heat transfer coefficient results of the SS-LC surface are about $20 \%$ higher than the HTC of the SS-HC and SS surfaces. This behavior seems mainly related to the fact that the roughness of the smooth surface increases with nanoparticle deposition, as shown in the surface images presented in Table 2, by splitting a single nucleation site into multiple ones, leading to an improvement in the boiling heat transfer, as depicted in Fig. 12. The present result agrees with the results of Narayan [18]. This author reported HTC enhancements with nanoparticles deposition when SIP > 1 . In the present study, the SIP value of the originally smooth surface is about 5 .

As the nanofluid concentration increases, the thermal resistance, due to the nanoparticle deposition on the heating surface, overlaps the effect of the surface roughness enhancement, implying the deterioration of the HTC, as showed in Fig. 11 for the SSHC surface. As already highlighted for the rough surfaces, according to the surface images depicted in Table 2, for the smooth surfaces, the deposition process with the nanofluid with the highest concentration also provides a thicker deposition layer than the nanofluid with the lowest nanoparticle concentration.

The surface roughness and the static contact angle measurements of the surfaces after the tests are given in Table 3. According to this table, the roughness of the coated surface and the static contact angle is a function of the nanofluid concentration and the original surface condition. As the nanofluid concentration increases the surface roughness also increases. Moreover, the contact angle decreases and, consequently, the wettability increases with increasing nanofluid concentration for both smooth and rough surfaces.

According to the results of the present study, the size of nanoparticles and heating surface morphology are more effective parameters that affect the heat transfer coefficient than the static contact angle. Sarafraz et al. [21] indicated that higher heat transfer coefficients can be obtained by changing the surface texture through a process of depositing nanoparticles and the key parameter for the CHF enhancement is related to the static contact angle modification.

Likewise, Hendricks et al. [30] also suggested that there is a balance between surface/fluid (capillarity effects) and surface/bubble dynamics, rather than surface morphology or hydrodynamics alone.

Adopting the same procedure as Saíz-Jabardo et al. [31], a regression analyses was performed in order to obtain values of $C_{s f}$ for the nanocoated surfaces evaluated in the present study, keeping the values of $r$ and $s$ equal to 0.33 and 1.0, respectively. These results are shown in Table 3, which also shows the surface-fluid parameter, $C_{s}$, estimated according to the method proposed by Li et al. [32] as follows:

$C_{s}=(1-\cos \theta)^{0.5}\left[1+\frac{5.45}{\left(R_{a}-3.5\right)^{2}+2.61}\right] \gamma^{-0.04}, \theta=\operatorname{MAX}\left(\theta, 15^{\circ}\right)$

where $\gamma=\sqrt{\frac{k_{s} \rho_{s} c_{p s}}{k_{l} c_{l} c_{p l}}}$ is the influence parameter of heating surface material. As pointed out by the authors [32], the effect of $\gamma$ is neg-

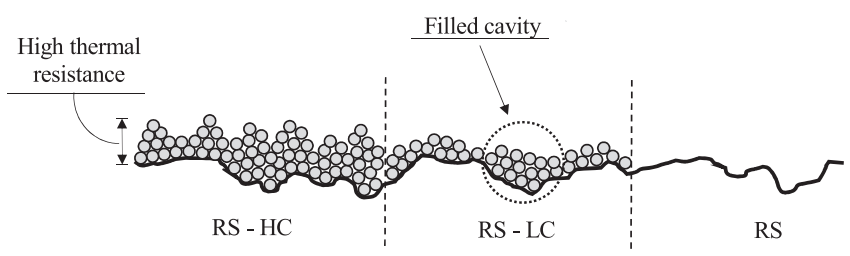

Fig. 10. Schematic drawing of nanoparticles deposition on the rough surface.
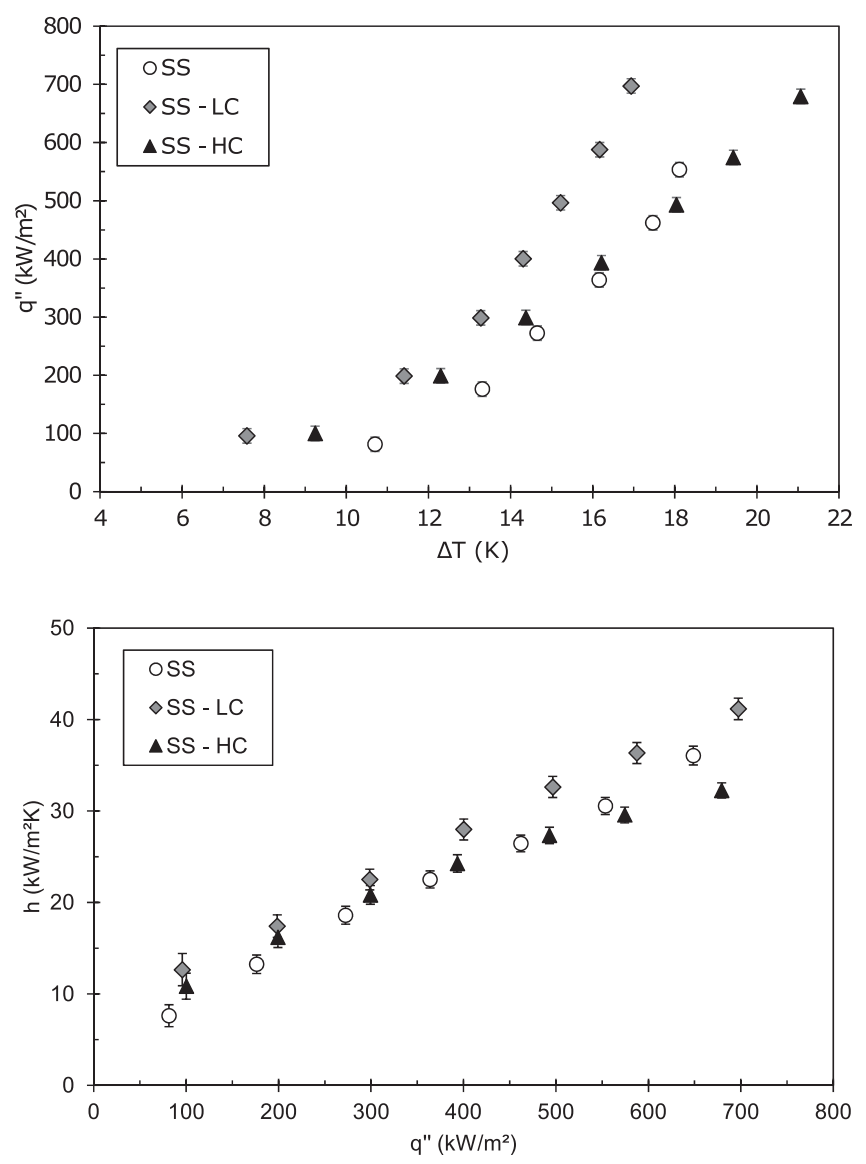

Fig. 11. Boiling curve and HTC curve for smooth surfaces with (SS-LC and SS-HC) and without (SS) nanoparticle deposition.

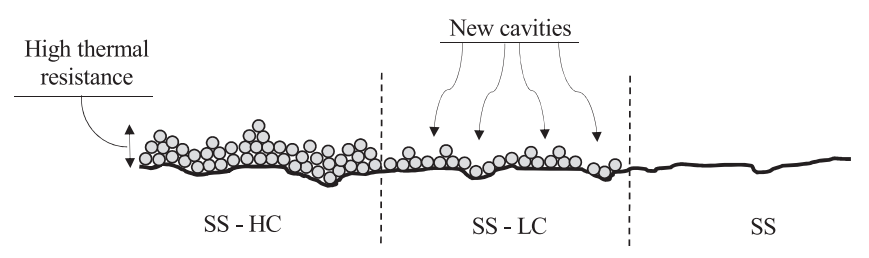

Fig. 12. Schematic drawing of nanoparticles deposition on the smooth surface.

ligible compared to the effects of $\theta$ and $R_{a}$. In fact, if the effect of $\gamma$ on HTC was taken into account according to the method of Li et al. [32] for water boiling on a copper surface, the heat transfer coefficient would increase by only $3 \%$. A lower increment of HTC is expected if the surface contacting the fluid is assumed as being of maghemite because the product of $k_{s} \rho_{s} c_{p s}$ for this material is lower than for copper. Moreover, it is unreasonable to assume maghemite in Eq. (4), because its layer is too thin to affect the transient mechanisms related to the heat diffusion within the wall during pool boiling.

Table 3 also presents the average surface-fluid parameters $C_{s}$ and its respective standard deviation for each surface sample considering only data for developed nucleate boiling as defined by Saíz-Jabardo et al. [31]. These values of $C_{s}$ were obtained from the heat transfer results based on the correlation presented by $\mathrm{Li}$ et al. [32] and given as follows:

$\frac{c_{p l} \Delta T_{s a t}}{h_{l v}}=0.013 C_{s}^{-0.33}\left[\frac{q^{\prime \prime}}{h_{l v} \mu_{l}} \sqrt{\frac{\sigma}{g\left(\rho_{l}-\rho_{v}\right)}}\right]^{0.33} \operatorname{Pr}_{l}$

According to the method of Rohsenow [26], the HTC is inversely proportional to the surface-fluid parameter while according to 
Table 3

Surface roughness, static contact angle and surface-fluid parameters, $C_{s f}$ and $C_{s}$.

\begin{tabular}{|c|c|c|c|c|c|}
\hline Surfaces & Surface roughness, $R_{a}(\mu \mathrm{m})$ & Contact angle, $\theta\left(^{\circ}\right)$ & $C_{s f}$ & $C_{s}$ from Eq. (4) & $C_{s} \pm \sigma^{\mathrm{a}}$ \\
\hline Smooth surface (SS) & 0.05 & $95^{\circ}$ & 0.0147 & 1.4342 & $0.67 \pm 0.09$ \\
\hline Rough surface (RS) & 0.23 & $75^{\circ}$ & 0.0107 & 1.2136 & $2.14 \pm 0.11$ \\
\hline SS-Low concentration (SS-LC) & 0.49 & $20^{\circ}$ & 0.0126 & 0.3603 & $1.15 \pm 0.04$ \\
\hline SS-High concentration (SS-HC) & 1.51 & $<10^{\circ}$ & 0.0148 & 0.3377 & $0.73 \pm 0.11$ \\
\hline RS-Low concentration (RS-LC) & 0.38 & $20^{\circ}$ & 0.0123 & 0.3540 & $1.11 \pm 0.06$ \\
\hline RS-High concentration (RS-HC) & 0.80 & $14^{\circ}$ & 0.0141 & 0.2862 & $0.75 \pm 0.05$ \\
\hline
\end{tabular}

a Estimated based on experimental results.

the method of Li et al. [32] the HTC increases with increasing $C_{s}$. To apply the method of Rohsenow [26] the surface-fluid parameter should be previously obtained based on pool boiling experimental results. Moreover, in this method the effects of surface roughness and contact angle are not explicit, while in the method of Li et al. [32], the surface-fluid parameter is estimated as an explicit function of the contact angle and surface roughness.

According to Table 3 and as already expected, $C_{s f}$ decreases and the value of $C_{s}$ estimated based on the experimental results increases with increasing the surface roughness for the surfaces without nanoparticles deposition. Curiously, the value of $C_{s}$ estimated according to Eq. (4) decreases with increasing the surface roughness. This behavior for the surfaces without deposition contradicts the behavior of the heat transfer experimental data.

By decreasing the contact angle, and consequently, increasing the wettability, it is expected that the liquid fills the larger cavities available on the surface deactivating them and suppressing nucleate boiling. This behavior would imply the increment of $C_{s f}$ and reduction of experimental $C_{s}$ due to the decrease of the number of active sites on the surface. However, according to Table 3 , it seems that the effect of the contact angle on the surface-liquid parameter for the surfaces without nanoparticle deposition is blurred due to the effect of large differences in the surface roughness. It should be also taken into account that the pair fluid-surface is the same in both cases and the contact angle difference is mainly due to the distinct surface finishing.

For the surfaces covered with nanoparticles, different $C_{s f}$ and $C_{s}$ behaviors, compared with the surfaces without deposition, are displayed in Table 3. Contrary to what is expected for surfaces without nanoparticle deposition, $C_{s f}$ increases and experimental $C_{s}$ decreases with increasing surface roughness, independently of the original surface roughness before the deposition.

Moreover, for the surfaces covered with nanoparticles, $C_{s f}$ increases and experimental $C_{s}$ decreases with decreasing contact angle according to the results presented in Table 3 . This behavior was already expected and is in agreement with literature. Unfortunately, considering that surface roughness and contact angle are both varying with deposition, it is not possible to segregate the effect of only one of these variables on the surface-fluid parameters based on the experimental results. This scenario is corroborated by the fact that superficial nanostructures and nanoporous matrixes generated through a boiling process may perform differently than a superficial finishing obtained through a simple polishing process using abrasive and emery paper. Moreover, the values of $C_{s f}$ and $C_{s}$ are also influenced by the additional thermal resistance resulting from the nanoparticles deposition on the surface which values were not evaluated in the present study.

In general, according to Table 3, Eq. (4) underestimates the effects of contact angle and surface roughness on the $C_{s}$ parameter for the surfaces covered with nanoparticles.

\section{Conclusions}

An analysis on the effect of surface roughness and nanofluid concentration on the HTC, using water as working fluid, were car- ried out. A metallographic, roughness and wettability characterization, after the deposition process by nanofluid pool boiling technique, were presented. The main results are summarized as follows:

Increasing the concentration of the nanofluid also increases the surface roughness;

$\checkmark$ The nanofluid pool boiling process causes an increase in the surface wettability independently of the original surface roughness. This behavior was noticed by the decrease of the static contact angle;

$\checkmark$ The coated layer formed on the rough surfaces provides a barrier to the heat transfer and reduces the bubble nucleation, which may lead to a reduction in the number of microcavities and an increase in the thermal resistance of the surface, therefore degrading the HTC;

$\checkmark$ For smooth surfaces, the deposition of nanoparticles tends to increase the nucleation sites density, increasing the boiling heat transfer. However, an increment in the HTC only occurs for low nanofluid concentrations, for which the effect of the thermal conductivity of the nanofluids is more dominant than the effect of the thermal resistance of the nanolayer formed on the heating surface.

$\checkmark$ Different $C_{s f}$ and $C_{s}$ behaviors were found for the surfaces covered with nanoparticles as compared with the surfaces without deposition. The values of $C_{s f}$ and $C_{s}$ are influenced by the additional thermal resistance resulting from the nanoparticles deposition on the surface which values were not evaluated in the present study. In general, the parameter of heating surface $C_{s}$, as expressed in Eq. (4), underestimate the effects of contact angle and surface roughness for the surfaces covered with nanoparticles.

\section{Acknowledgments}

The authors are grateful for the financial support from the PPGEM - UNESP/FEIS, from the National Counsel of Technological and Scientific Development of Brazil (CNPq grant number 458702/2014-5) and from FAPESP (grants numbers 2013/154317, 2014/07949-9 and 2014/19497-5). The authors also extend their gratitude to Mrs. Maria de Fátima da Silva and Mr. Marcelo Parise from NFA Laboratory in the Physics Institute of the University of Brasília for supplying the nanofluids.

\section{References}

[1] W. Fritz, Maximum volume of vapor bubbles, Phys. Z. 36 (1935) 379-384.

[2] Y.M. Yang, J.R. Maa, Boiling of suspension of solid particles in water, Int. J. Heat Mass Transf. 27 (1984) 145-147.

[3] L. Cheng, E.P. Bandarra Filho, J.R. Thome, Nanofluid two-phase flow and thermal physics: a new research frontier of nanotechnology and its challenges, J. Nanosci. Nanotechnol. 8 (2008) 3315-3332.

[4] S. Vafaei, Nanofluid pool boiling heat transfer phenomenon, Powder Technol. 277 (2015) 181-192.

[5] D. Ciloglu, A. Bolukbasi, A comprehensive review on pool boiling of nanofluids, Appl. Therm. Eng. 84 (2015) 45-63. 
[6] N. Dinh, J. Tu, T. Theofanous, Hydrodynamic and physico-chemical nature of burnout in pool boiling, in: Proceedings of the 5th Int. Conf. on Multiphase Flow, Yokohama, Japan, 2004.

[7] D. Wen, Y. Ding, Experimental investigation into the pool boiling heat transfer of aqueous based $\gamma$-alumina nanofluids, J. Nanopart. Res, 7 (2005) 265-274.

[8] L.V. Heitich, J.C. Passos, E.M. Cardoso, M.F. Silva, A.N. Klein, Nucleate boiling of water using nanostructured surfaces, J. Braz. Soc. Mech. Sci. Eng. 36 (2014) 181-192.

[9] R.R. Souza, J.C. Passos, E.M. Cardoso, Influence of nanoparticle size and gap size on nucleate boiling using HFE7100, Exp. Thermal Fluid Sci. 59 (2014) 195-201.

[10] I.C. Bang, S.H. Chang, Boiling heat transfer performance and phenomena of $\mathrm{Al}_{2} \mathrm{O}_{3}$ - water nanofluids from a plain surface in a pool, Int. J. Heat Mass Transf. 48 (2005) 2407-2419.

[11] S.J. Kim, I.C. Bang, J. Buongiorno, L.W. Hu, Surface wettability change during pool boiling of nanofluids and its effect on critical heat flux. Int. J. Heat Mass Transf. 50 (2007) 4105-4116.

[12] O. Ahmed, M.S. Hamed, Experimental investigation of the effect of particle deposition on pool boiling of nanofluids, Int. J. Heat Mass Transf. 55 (2012) 3423-3436.

[13] H.D. Kim, M.H. Kim, Effect of nanoparticle deposition on capillary wicking that influences the critical heat flux in nanofluids, Appl. Phys. Lett. 91 (2007) 014104.

[14] M.N. Golubovic, H.M. Hettiarachchi, W.M. Worek, W.J. Minkowycz, Nanofluids and critical heat flux, experimental and analytical study, Appl. Therm. Eng. 29 (2009) 1281-1288.

[15] I.S. Kiyomura, F.J. Nascimento, A.P. Cunha, E.M. Cardoso, Analysis of the influence of surface roughness and nanoparticle concentration on the contact angle, in: Proceedings of 23rd ABCM International Congress of Mechanical Engineering, Rio de Janeiro, Brazil, 2015.

[16] S.D. Park, S.B. Moon, I.C. Bang, Effects of thickness of boiling-induced nanoparticle deposition on the saturation of critical heat flux enhancement, Int. J. Heat Mass Transf. 78 (2014) 506-514.

[17] I. Ignácio, E.M. Cardoso, J.L. Gasche, G. Ribatski, A state-of-art review on pool boiling on nanostructured surfaces, in: Proceedings of the ASME 2015 International Technical Conference and Exhibition on Packaging and Integration of Electronic and Photonic Microsystems and ASME 2015 13th International Conference on Nanochannels, Microchannels, and Minichannels, San Francisco, California, USA, 2015.
[18] G.P. Narayan, K.B. Anoop, S.K. Das, Mechanism of enhancement/deterioration of boiling heat transfer using stable nanoparticle suspensions over vertica tubes, J. Appl. Phys. 102 (2007) 074317.

[19] G. Harish, V. Emlin, V. Sajith, Effect of surface particle interactions during pool boiling of nanofluids, Int. J. Therm. Sci. 50 (2011) 2318-2327.

[20] M.R. Raveshi, A. Keshavarz, M.S. Mojarrad, S. Amiri, Experimental investigation of pool boiling heat transfer enhancement of alumina-water-ethylene glyco nanofluids, Exp. Thermal Fluid Sci. 44 (2013) 805-814.

[21] M.M. Sarafraz, F. Hormozi, S.M. Peyghambarzadeh, Pool boiling heat transfer to aqueous alumina nano-fluids on the plain and concentric circular microstructured (CCM) surfaces, Exp. Thermal Fluid Sci. 72 (2016) 125-139.

[22] R. Massart, Magnetic fluids and process for obtain them, US Patent 4329241 1982.

[23] J.C. Passos, R.F. Reinaldo, Analysis of pool boiling within smooth and grooved tubes, Exp. Thermal Fluid Sci. 22 (2000) 35-44.

[24] B.N. Taylor, C.K. Kuyatt, Guidelines for Evaluating and Expressing the Uncertainty of NIST Measurement Results. NIST Technical Note 1297 National Institute of Standards and Technology, 1994.

[25] F.P. Netto, A.A.U. Moraes, U. Ribatski, The effects of the nanoparticle concentration and surface roughness on the contact angle of nanofluids, in: Proceedings of 22nd ABCM International Congress of Mechanical Engineering Ribeirão Preto, Brazil, 2013.

[26] W.M. Rohsenow, A method of correlating heat transfer data for surface boiling of liquids, Trans. ASME J. Heat Transfer 74 (1952) 969-976.

[27] R.I. Vachon, G.H. Nix, G.E. Tanger, Evaluation of constants for the Rohsenow pool-boiling correlation, J. Heat Transfer 90 (2) (1968) 239-246.

[28] K. Stephan, Heat Transfer in Condensation and Boiling, Springer-Verlag, Berlin, 1992.

[29] C. Corty, A.S. Foust, Surface variables in nucleate boiling, Chem. Eng. Prog. Symp. Series 51 (1995) 1-12.

[30] T.J. Hendricks, S. Krishnan, C. Choi, C. Chang, B. Paul, Enhancement of poolboiling heat transfer using nanostructured surfaces on aluminum and copper Int. J. Heat Mass Transf. 53 (2010) 3357-3365.

[31] J.M. Jabardo, E. Silva, G. Ribatski, S.F. de Barros, Evaluation of the Rohsenow correlation through experimental pool boiling of halocarbon refrigerants on cylindrical surfaces, J. Braz. Soc. Mech. Sci. Eng. 26 (2004) 218-230.

[32] Y.Y. Li, Y.J. Chen, Z.H. Liu, A uniform correlation for predicting pool boiling heat transfer on plane surface with surface characteristics effect, Int. J. Heat Mass Transf. 77 (2014) 809-817. 